November - 2009

\title{
Open Access Week
}

\section{Terry Anderson}

The publication of this special issue on openness coincides with the first international Open Access Week, held from Oct. 19-23, 2009. IRRODL's sponsor, Athabasca University, participated in this event by hosting five noon-hour web conferences, which were presented by internationally known experts on various components of openness. The sessions were hosted by Elluminate.com.

The archives of these events contain recordings of the Elluminate sessions, MP3 and MP4 podcasts, and the slides used by the presenters. The five presentations are as follows: The Open Access Scholar, Open Access Research Opportunities and Strategies, Open Access Publication, Open Access Archives and Repositories, and Open Educational Resources. IRRODL readers are invited to visit Atahabasca University's Open Access Week archives.

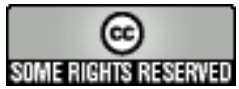

